\title{
Case study: Possible differences in phthalates exposure among the Czech, Hungarian, and Slovak populations identified based on the DEMOCOPHES pilot study results
}

\author{
Milena Černáa,b,*, Marek Malýa ${ }^{a}$, Peter Rudnai ${ }^{c}$, Szilvia Középesy ${ }^{c}$, Miklós Náray ${ }^{\text {d }}$, \\ Katarina Halzlová ${ }^{e}$, Michal Jajcaj ${ }^{e}$, Anna Grafnetterováa ${ }^{a}$, Andrea Krskováa \\ Danuše Antošová a ${ }^{\text {, }}$ Kateřina Forysová ${ }^{\mathrm{f}}$, Elly Den Hond ${ }^{\mathrm{o}}$, Greet Schoeters ${ }^{\mathrm{g}, \mathrm{l}}$, Reinhard Joas ${ }^{\mathrm{h}}$, \\ Ludwine Casteleyn $^{\mathrm{i}}$, Anke Joas ${ }^{\mathrm{h}}$, Pierre Biot ${ }^{\mathrm{j}}$, Dominique Aerts ${ }^{\mathrm{j}}$, Jürgen Angerer ${ }^{\mathrm{k}}$, \\ Louis Bloemen $^{\mathrm{m}}$, Argelia Castaño ${ }^{\mathrm{n}}$, Marta Esteban ${ }^{\mathrm{n}}$, Holger M. Koch ${ }^{\mathrm{k}}$, \\ Marike Kolossa-Gehring ${ }^{\mathrm{p}}$, Arno C. Gutleb ${ }^{\mathrm{q}}$, Jana Pavloušková ${ }^{\mathrm{a}}$, Karel Vrbík ${ }^{\mathrm{a}}$ \\ a National Institute of Public Health, Šrobárova 48, Prague 10100 42, Czech Republic \\ b Charles University, Third Faculty of Medicine, Prague, Czech Republic \\ ${ }^{\mathrm{c}}$ National Institute of Environmental Health, Budapest, Hungary \\ ${ }^{\mathrm{d}}$ National Labour Office, Department for Occupational Health, Budapest, Hungary \\ e Authority of Public Health of the Slovak Republic, Bratislava, Slovakia \\ ${ }^{\mathrm{f}}$ Public Health Agency based in Liberec, Czech Republic \\ ${ }^{g}$ VITO, Environmental Risk and Health Unit, Boeretang 200, 2400 Mol, Belgium \\ h BiPRO, Munich, Germany \\ ${ }^{\mathrm{i}}$ KU Leuven-Centrum Menselijke Erfelijkheid, Belgium \\ ${ }^{\mathrm{j}}$ Federal Public Service Health, Food Chain Safety and Environment-DG Environment, Brussels, Belgium \\ ${ }^{\mathrm{k}}$ Institute for Prevention and Occupational Medicine of the German Social Accident Insurance-Institute of the Ruhr-Universität Bochum (IPA), Germany \\ ${ }^{1}$ Department of Biomedical Sciences, University of Antwerp, Antwerp, Belgium \\ ${ }^{\mathrm{m}}$ Environmental Health Sciences International, Hulst, The Netherlands \\ ${ }^{\mathrm{n}}$ Instituto de Salud Carlos III, Madrid, Spain \\ o Flemish Institute for Technological Research (VITO), Environmental Risk and Health, Belgium \\ ${ }^{\mathrm{p}}$ Federal Environment Agency (UBA), Berlin, Germany \\ ${ }^{\mathrm{q}}$ Centre de Recherche Public-Gabriel Lippmann, Belvaux, Luxembourg
}

\section{A R T I C L E I N F O}

\section{Article history:}

Received 4 August 2014

Received in revised form

23 September 2014

Accepted 15 October 2014

Keywords:

DEMOCOPHES

Urinary phthalate metabolites

Czech Republic

Slovakia

Hungary

\begin{abstract}
A B S T R A C T
Objective: Phthalates and their metabolites are classified as endocrine modulators. They affect the hormonal balance in both children and adults.

The aim of this publication was to compare the urinary levels of phthalate metabolites in selected populations of the Czech Republic (CZ), Slovakia (SK), and Hungary (HU) in relation to the sources of phthalate exposure identified by means of questionnaire (personal care products, floor and wall coverings, plastic toys, and some kinds of foods).

Methods: Data were obtained through the twin projects COPHES (COnsortium to Perform Human biomonitoring on a European Scale) and DEMOCOPHES (DEMOnstration of a study to COordinate and Perform Human biomonitoring on a European Scale) from 2009 to 2012. The target groups were children aged 6-11 years old and their mothers up to 45 years of age. The metabolites of phthalates (monomethyl phthalate (MMP), monoethyl phthalate (MEP), monobenzyl phthalate (MBzP), mono-cyclohexyl phthalate (MCHP), mono-(2ethylhexyl) phthalate (MEHP), mono-(2-ethyl-5-hydroxyhexyl) phthalate (5OH-MEHP), and mono-(2-ethyl-5oxohexyl) phthalate (5OXO-MEHP)) were analysed in first morning urine samples. After enzymatic glucuronide cleavage, the urine sample analyses were performed using ultra-high-performance liquid chromatographyelectrospray ionization tandem mass spectrometry (UHPLC-ESI-MS/MS) in one laboratory that qualified in the External Quality Assessment exercises organised by COPHES.

Results: Significant differences in phthalate exposure between countries were revealed for children only but not for mothers. The concentrations of 5-OH-MEHP $(P<0.001), 50 X O-M E H P(P<0.001)$, and their sum $(P<0.001)$ were the highest in SK compared to $\mathrm{CZ}$ and $\mathrm{HU}$. The health based guidance values for the sum of
\end{abstract}

\footnotetext{
* Corresponding author at: National Institute of Public Health, Šrobárova 48, Prague 10100 42, Czech Republic.

E-mail address: mcerna@szu.cz (M. Černá).
} 
DEHP metabolites 5-OH MEHP and 50XO-MEHP established by the German Commission for biomonitoring of $300 \mu \mathrm{g} / \mathrm{L}$ and $500 \mu \mathrm{g} / \mathrm{L}$ for women adults and children, respectively, were only exceeded in one mother and three boys. A significant difference was also found for MEP $(P=0.0149)$, with the highest concentrations detected in $\mathrm{HU}$. In all countries, the increasing frequency of using personal care products significantly elevated the concentrations of MEP.

Conclusion: Some differences were observed between countries in the concentrations of individual urinary phthalate metabolites in children. However, the questionnaire results give no direct explanation for the differences between the countries except the variation in using personal care products.

(c) 2014 Elsevier Inc. All rights reserved.

\section{Introduction}

Human biomonitoring (HBM) is a tool for evaluating population exposure to potentially critical chemicals found in the environment, contaminated foodstuffs, lifestyle, use of different products, and other sources. This approach allows characterising the body burden from all exposure sources and has been increasingly applied in environmental health surveys in the last decade all over the world (Angerer et al., 2007; Needham et al., 2007).

Although HBM has been practiced for several years in several European countries (Becker et al., 2002, 2003; Černá et al., 2007; Fréry et al., 2012; Cañas, et al., 2014; Schindler et al., 2014), Europe as such-unlike the USA (CDC, 2013)-has no comparable data on the levels of environmental chemicals in the body for their population. Results produced by individual European countries are not always comparable as the studies may differ in the methodological steps like recruitment of body fluid donors, choice of population groups, selection of biomarkers and analytical procedures.

Therefore, the European Environment and Health Action Plan 2004 prioritized the need to harmonise HBM in Europe to be able to obtain internationally comparable data (EHAP, 2004; Joas et al., 2012). Unified protocols developed by the COPHES project (COnsortium to Perform Human biomonitoring on a European Scale) and the practical use of these Standard operational procedures (SOPs) in the DEMOCOPHES project (DEMOnstration of a study to COordinate and Perform Human biomonitoring on a European Scale) allowed to produce comparable data by means of harmonized methodological procedures within the DEMOCOPHES pilot study (Becker et al., 2014; Schindler et al., 2014).

For the DEMOCOPHES pilot study, children aged between 6 and 11 years old were chosen as the main target group. The reason being that children belong to the most vulnerable population group, and that the protection of children's health is a main priority for the environmental health policy. The exposure of infants and children to environmental toxic compounds early on in life may adversely influence their quality of life in later periods (Au, 2002). Additionally, the children's mothers were included. The population group of mothers as women of reproductive age is another known vulnerable group with similar lifestyle characteristics and habits to the children under study.

Several environmental pollutants with known biomarkers of exposure (cadmium and cotinine in urine and mercury in hair) were selected for the DEMOCOPHES pilot study based on ongoing knowledge of HBM requirements taking into account the demands of participating countries discussed in the Consultative Forum in the frame of the EU Environment and Health Action Plan (Becker et al., 2014; Joas et al., 2012). Contrary to the existing HBM scenarios in which generally the population exposure to traditional environmental pollutants covered by sufficient analytical experience like heavy metals or persistent organic pollutants is monitored, this pilot study also included phthalates. They represent a relatively new group of emerging types of environmental contaminants, identified due to increasing public and political awareness (Zimmer et al., 2012), which started to be included into the spectrum of monitored biomarkers only in the last decade (Barr et al., 2003; Koch et al., 2003a).

Some phthalates such as di(2-ethylhexyl) phthalate (DEHP) have been widely used as plasticizers in numerous products (Lyche et al., 2009). Other phthalate derivatives are also used for different purposes dependent on their molecular weight, e.g. as additives in the textile industry (DEHP, di-isononyl phthalate (DiNP), and di-isodecyl phthalate (DiDP), etc.), personal care products (dimethyl phthalate (DMP), diethyl phthalate (DEP), di- $n$-butyl phthalate (DBP), etc.), paints and construction materials (DiNP, DiDP) or adhesives (ATSDR, 2002; Heudorf et al., 2007). At present, the US general population is exposed to phthalates to quite a large extent (Hauser and Calafat, 2005). As phthalates are classified as endocrine disruptors and reproductive toxicants, the exposure of children is of particular concern (Swan et al., 2005). Phthalates enter the human body by ingestion, inhalation and dermal absorption (Wittassek et al., 2011). They are quickly metabolised in the organism and metabolites are excreted in urine (Koch et al., 2006). Urinary metabolites of phthalates are considered relevant indicators of phthalate exposure (Koch et al., 2003b, 2006). Therefore metabolites were included in the range of biomarkers monitored in the DEMOCOPHES pilot study. At the beginning of this study, only very few laboratories were able to analyse the most important metabolites of phthalates so as to match Interlaboratory Comparison Investigation/External Quality Assessment Scheme (ICI/ EQUAS) tests (Schindler et al., 2014). The laboratory of the National Institute of Public Health (NIPH) in Prague was one of the few which succeeded in the ICI/ EQUAS exercise). Therefore, the analyses of selected phthalate metabolites in the samples from the Czech Republic, Slovakia and Hungary were performed in the NIPH laboratory.

Data regarding the concentration of urinary phthalate metabolites obtained in the Democophes study for all 17 participating European countries have shown marked differences and the highest mean urinary DEPH metabolite concentrations were found in children from Slovakia (Den Hond et al., unpublished data). Therefore the main objective of this manuscript was to try to identify the possible causes of this finding taking into account responses obtained in basal questionnaire (Fiddicke et al., this issue) and explain higher concentrations of urinary phthalate metabolites in Slovak children compared with neighbouring states.

\section{Materials and methods}

\subsection{Sampling and questionnaire}

In the Czech Republic and Hungary, 120 pairs of children aged 6 to 11 years old and their mothers from urban and rural areas each were examined while in Slovakia 129 such pairs were enrolled. In all three countries study subjects were recruited through schools, equally in urban and rural areas as defined according to regional standards. Generally samples and sampling were not 
population representative, because the general HBM approach and the feasibility of using a unified protocol all over Europe was in the focus of COPHES and DEMOCOPHES. Information on study population characteristics and potential determinants of exposure were obtained through personalized interviews (Table 1). Trained field workers visited families in their homes at times that would suit the families to collect paired maternal and child morning urine and hair samples in accordance with COPHES SOPs and to carry out the questionnaire directly with the mothers.

Basic questionnaire (BQ) was developed concerning exposure pathways for the biomarkers included to the study (Fiddicke et al., this issue). Questions regarding potential exposure to phthalates concerned household equipment (e.g. PVC floor, renovation of flat or house, nutrition (namely convenience or fast food, ice cream, local food etc.), use of personal care products, use of plastic gloves, and playing with plastic toys (children). Other lifestyle factors like

Table 1

Descriptive statistics of mothers and children enrolled in the study.

\begin{tabular}{|c|c|c|c|c|c|c|}
\hline & \multicolumn{3}{|l|}{ Mothers } & \multicolumn{3}{|c|}{ Children } \\
\hline & $\mathrm{CZ}$ & $\mathrm{HU}$ & SK & $\mathrm{CZ}$ & $\mathrm{HU}$ & SK \\
\hline collected samples & 120 & 120 & 129 & 120 & 120 & 129 \\
\hline $\begin{array}{l}N \text {-analysed } \\
\text { samples }\end{array}$ & 117 & 115 & 125 & 120 & 117 & 127 \\
\hline Mean age (range) & $\begin{array}{l}37.5 \\
(29-45)\end{array}$ & $\begin{array}{l}36.4 \\
(26-45)\end{array}$ & $\begin{array}{l}37.0 \\
(24-46)\end{array}$ & $\begin{array}{l}8.4 \\
(6-11)\end{array}$ & $\begin{array}{l}8.5 \\
(6-11)\end{array}$ & $\begin{array}{l}8.4 \\
(6-11)\end{array}$ \\
\hline \multicolumn{7}{|l|}{ Creatinine [mg/L] } \\
\hline$<300^{\mathrm{a}}$ & 3 & 3 & 2 & 0 & 2 & 0 \\
\hline $300-3000$ & 117 & 115 & 125 & 120 & 117 & 127 \\
\hline$>3000^{\mathrm{a}}$ & 0 & 2 & 2 & 0 & 1 & 2 \\
\hline \multicolumn{7}{|l|}{ Age group } \\
\hline$<=35$ years & 37 & 47 & 45 & - & - & - \\
\hline $35-40$ years & 56 & 45 & 51 & - & - & - \\
\hline$>40$ years & 24 & 23 & 29 & - & - & - \\
\hline $6-8$ year & - & - & - & 61 & 59 & 66 \\
\hline 9-11 years & - & - & - & 59 & 58 & 61 \\
\hline \multicolumn{7}{|l|}{ Gender } \\
\hline Boys & - & - & - & 59 & 59 & 66 \\
\hline Girls & - & - & - & 61 & 58 & 61 \\
\hline \multicolumn{7}{|l|}{ Smoking status } \\
\hline Daily smoker & 13 & 29 & 15 & - & - & - \\
\hline Occasional smoker & 11 & 8 & 8 & - & - & - \\
\hline Ex-smoker & 18 & 18 & 21 & - & - & - \\
\hline Never smoker & 78 & 65 & 85 & - & - & - \\
\hline \multicolumn{7}{|l|}{ Education } \\
\hline Primary (ISCED 0-2) & 1 & 1 & 1 & - & - & - \\
\hline $\begin{array}{l}\text { Secondary (ISCED 3- } \\
4 \text { ) }\end{array}$ & 65 & 72 & 68 & - & - & - \\
\hline Tertiary (ISCED 5-6) & 54 & 46 & 60 & - & - & - \\
\hline \multicolumn{7}{|c|}{ Highest education in family } \\
\hline Primary (ISCED 0-2) & 3 & 4 & 0 & - & - & - \\
\hline $\begin{array}{l}\text { Secondary (ISCED 3- } \\
4 \text { ) }\end{array}$ & 51 & 63 & 55 & - & - & - \\
\hline Tertiary (ISCED 5-6) & 66 & 52 & 74 & - & - & - \\
\hline \multicolumn{7}{|c|}{ Alcohol consumption ${ }^{\mathrm{b}}$} \\
\hline Mean (range) & $\begin{array}{l}2.4(0- \\
17)\end{array}$ & $\begin{array}{l}0.8(0- \\
14)\end{array}$ & $\begin{array}{l}1.0(0- \\
8)\end{array}$ & - & - & - \\
\hline
\end{tabular}

ISCED-International Standard Classification of Education.

${ }^{\text {a }}$ Excluded from study.

b According to DEMOCOPHES, in units per week. smoking, alcohol consumption, sources of drinking water etc. were also followed.

The study was approved by the Ethical Committees in each of the participating countries and all mothers recruited gave informed written consent to participate in the study.

\subsection{Determination of phthalate metabolites}

Biomarkers in DEMOCOPHES samples could be analysed by labs that were successful in at least one ICI and one EQUAS exercise or two EQUAS exercises. The laboratory that actually carried out the analyses successfully qualified in the External Quality Assessment exercises organised by COPHES (Schindler et al., 2014).

According to the requirements of the COPHES/DEMOCOPHES coordination team, nine phthalate metabolites, as listed in Table 2 , and their labelled analogues (D or 13C) were purchased from Sigma-Aldrich, Dr. Ehrenstorfer, and Cambridge Isotope Laboratories or were a generous gift from Professor Jürgen Angerer (University of Erlangen, Nuremberg, Germany); $\beta$-glucuronidase was purchased from Roche.

Human urine samples were collected in glass vials and stored at $-18{ }^{\circ} \mathrm{C}$ prior to analysis. Half millilitre of urine sample was processed using published procedures (Blount et al., 2000; Koch et al., 2003b) with enzymatic cleavage of glucuronide. For the calibration, water solutions with concentrations from 0.5 to $200 \mu \mathrm{g} / \mathrm{L}$ were prepared. The internal standards were added to all calibration solutions and the samples. In this study, we took advantage of the available instrumentation and therefore, the samples after incubation with $\beta$-glucuronidase were not concentrated, but only diluted with a mobile phase and injected $(20 \mu \mathrm{L})$, which led to satisfactory limits of detection (LODs).

The analyses were performed using ultra-high-performance liquid chromatography electrospray ionization triple quadrupole tandem mass spectrometry (UHPLC-ESI-MS/MS) (Agilent Technologies). The ion source was Jet Stream ESI. The chromatograph was equipped with an analytical column (Poroshell 120 SB-C18, $2.7 \mu \mathrm{m}, 150 \times 3 \mathrm{~mm}$ ). The mobile phase gradient consisted of $1 \%$ acetic acid and acetonitrile. Another chromatographic column, Zorbax Eclipse Plus C18 Rapid Resolution HD, $1.8 \mu \mathrm{m}, 50 \times 2.1 \mathrm{~mm}$, was inserted between the binary pump and autosampler and was used as a trap to capture interferences from the mobile phase, and to delay them as compared with the metabolites from injection.

Table 2

Phthalate metabolites analysed in urine samples from the $\mathrm{CZ}, \mathrm{HU}$, and SK within the DEMOCOPHES pilot study.

\begin{tabular}{|c|c|c|c|}
\hline $\begin{array}{l}\text { Parental } \\
\text { phthalate }\end{array}$ & Metabolites & Acronyms & Note \\
\hline DMP & Monomethyl phthalate & MMP & $\begin{array}{l}\text { More than } 50 \% \\
\text { below LOQ }\end{array}$ \\
\hline DEP & Monoethyl phthalate & MEP & \\
\hline $\mathrm{DBP}$ & Mono-n-butyl phthalate & MnBP & $*$ \\
\hline \multirow[t]{2}{*}{ BzBP } & Monobenzyl phthalate & MBzP & \\
\hline & Mono-n-butyl phthalate & MnBP & $*$ \\
\hline DCHP & Monocyclohexyl phthalate & MCHP & $\begin{array}{l}\text { More than } 90 \% \\
\text { below LOQ }\end{array}$ \\
\hline \multirow[t]{3}{*}{ DEHP } & $\begin{array}{l}\text { Mono(2-ethylhexyl) } \\
\text { phthalate }\end{array}$ & MEHP & \\
\hline & $\begin{array}{l}\text { Mono(2-ethyl-5-hydro- } \\
\text { xyhexyl) phthalate }\end{array}$ & 5ОН-МЕНР & \\
\hline & $\begin{array}{l}\text { Mono(2-ethyl-5-oxohexyl) } \\
\text { phthalate }\end{array}$ & 5ОХO-МЕHР & \\
\hline
\end{tabular}

*Both metabolites MnBP and MiBP were measured, but are not listed due to doubts about their proper resolution. In fact, MnBP results were successfully evaluated in the frame of EQUAS organized by COPHES, but the data on MiBP were not sent to EQUAS for evaluation. 
Table 3

Performance parameters of analytical method.

\begin{tabular}{|c|c|c|c|c|c|c|c|c|}
\hline Parameter & MMP & MEP & MnBP & $\mathrm{MBzP}$ & MCHP & MEHP & $\begin{array}{l}50 H- \\
\text { MEHP }\end{array}$ & $\begin{array}{l}\text { 5OXO- } \\
\text { MEHP }\end{array}$ \\
\hline $\mathrm{LOD}[\mu \mathrm{g} / \mathrm{L}]$ & 0.09 & 0.2 & 0.5 & 0.4 & 0.07 & 0.7 & 0.2 & 0.08 \\
\hline $\mathrm{LOQ}[\mu \mathrm{g} / \mathrm{L}]$ & 0.27 & 0.6 & 1.5 & 1.2 & 0.2 & 2.0 & 0.6 & 0.24 \\
\hline$r_{2}[\%]$ & 12 & 9 & 9 & 7 & 7 & 4 & 5 & 5 \\
\hline$r_{20}[\%]$ & 6 & 4 & 4 & 5 & 4 & 2 & 3 & 3 \\
\hline$r_{150}[\%]$ & 5 & 3 & 4 & 6 & 6 & 2 & 4 & 7 \\
\hline$R_{2}[\%]$ & 110 & 82 & 110 & 97 & 87 & 73 & 105 & 94 \\
\hline$R_{20}[\%]$ & 99 & 93 & 87 & 103 & 91 & 90 & 105 & 97 \\
\hline$R_{150}[\%]$ & 102 & 95 & 90 & 103 & 94 & 96 & 106 & 100 \\
\hline
\end{tabular}

The quality of the measurements was checked not only in ICI/ EQUAS, but also blanks and quality control samples were added to every round of measurements.

The performance characteristics according to the requests from the COPHES project were assessed (see results in Table 3): limits of detection (LOD) and quantification (LOQ), repeatability $(r)$ expressed as relative standard deviation (RSD) at three concentration levels. No reference materials were available, so the exactitude had to be assessed as recovery $(R)$. The results are adequate for testing DEMOCOPHES samples.

The creatinine analysis was provided by the accredited laboratory using an already published method (Schneiderka et al., 1993). This laboratory also achieved good results in EQUAS. The sample diluted with water was analysed by liquid chromatography coupled to a diode array detector (HPLC-DAD).

Urinary biomarkers are expressed either as a concentration $(\mu \mathrm{g} / \mathrm{L})$ or as a creatinine-corrected value ( $\mu \mathrm{g} / \mathrm{g}$ of creatinine).

\subsection{Statistical analysis}

Analysed data were derived from the COPHES/DEMOCOPHES European central database. Samples with creatinine concentrations below $300 \mathrm{mg} / \mathrm{L}$ or above $3000 \mathrm{mg} / \mathrm{L}$ (WHO, 1996) were excluded from statistical analyses (Table 1 ). Phthalate metabolite concentrations below the LOQ were replaced with 1/2 LOQs.
Metabolite concentrations are presented as geometric means with $95 \%$ confidence intervals. Between-group comparisons were based on various models of analysis of variance and covariance applied to the natural logarithm-transformed data. In case of significant results, Sidak's multiple comparison procedure was used to determine which pairs of groups differ. Unadjusted and adjusted comparisons among countries were done. Covariates included in the models were age, gender (children only), industry with possible contamination of phthalates in neighbourhood of residence, vinyl flooring, main source of drinking water, milk consumption, use of personal care products (mothers only), and use of shampoo (children only). For urinary biomarkers expressed as a concentration $(\mu \mathrm{g} / \mathrm{L})$ the extension by creatinine used as a covariate was also considered.

Associations between mothers and children were quantified by the Spearman correlation coefficients. The inter-country differences in the relationship between the values of mothers and children were tested using the interaction term in a model where the maternal values and country were independent variables, and the child's values the dependent variable. For categorical data, the differences in proportions among the groups were analysed using Fisher's exact test. All statistical tests were evaluated as two-sided at a significance level of 0.05 . Statistical analysis was performed by the statistical software Stata, release 9.2 (Stata Corp LP, College Station, TX).

\section{Results and discussion}

\subsection{BASIC characteristics of the children and mothers}

Descriptive statistics of the children and mothers from $\mathrm{CZ}$, HU and SK included in the study are presented in Table 1. According to the European study protocol, study subjects were equally recruited by the predefined strata of gender, age, and sampling area in each country. Therefore, the three countries did not differ in the gender distribution of children or in the age distribution of mothers and children.

Table 4

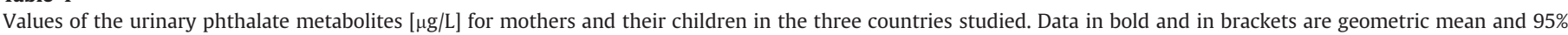
confidence interval.

\begin{tabular}{|c|c|c|c|c|c|c|}
\hline & \multicolumn{2}{|l|}{$\mathbf{C Z}$} & \multicolumn{2}{|l|}{ SK } & \multicolumn{2}{|l|}{ HU } \\
\hline & Mothers $(N=117)$ & Children $(N=120)$ & Mothers $(N=125)$ & Children $(N=127)$ & Mothers $(N=115)$ & Children $(N=117)$ \\
\hline МЕHР & 3.33 (2.87; 3.87$)$ & $3.80(2.65 ; 3.59)$ & 3.96 (3.38; 4.64) & $3.95(3.35 ; 4.65)$ & $3.83(3.18 ; 4.61)$ & $3.65(3.6 ; 4.35)$ \\
\hline$\%<L O Q$ & 23.9 & 27.5 & 20.0 & 22.1 & 25.2 & 24.8 \\
\hline 5ОН-МЕНР & $19.62(17.16 ; 22.42)$ & $\mathbf{3 6 . 9 8}(32.52 ; 42.05)$ & $22.40(19.66 ; 25.53)$ & $49.30(43.39 ; 56.00)$ & $19.37(16.47 ; 22.79)$ & $33.65(28.94 ; 39.11)$ \\
\hline$\%<L O Q$ & 0 & 0 & 0 & 0 & 0 & 0 \\
\hline 50ХО-МЕНP & $12.42(10.93 ; 14.11)$ & $24.77(21.73 ; 28.24)$ & $14.21(12.49 ; 16.17)$ & $33.26(29.23 ; 37.86)$ & $12.93(11.00 ; 15.20)$ & $22.91(19.71 ; 26.63)$ \\
\hline$\%<L O Q$ & 0 & 0 & 0 & 0 & 0 & 0 \\
\hline MEP & $\mathbf{5 6 . 6 6}(43.68 ; 73.48)$ & $31.60(26.27 ; 38.01)$ & $\mathbf{5 4 . 8 1}(44.15 ; 68 ; 04)$ & 39.64 (33.39; 47.06) & $\mathbf{5 5 . 0 4}(44.17 ; 68.58)$ & $\mathbf{4 6 . 9 8}(38.25 ; 57.70)$ \\
\hline$\%<L O Q$ & 0 & 0 & 0 & 0 & 0 & 0 \\
\hline MBzP & $4.62(3.68 ; 5.81)$ & $8.32(6.89 ; 10.40)$ & $4.70(4.10 ; 5.50)$ & $8.35(7.10 ; 9.82)$ & $4.76(4.20 ; 5.65)$ & $7.57(6.21 ; 9.23)$ \\
\hline$\%<L O Q$ & 9.4 & 0 & 4.8 & 0.8 & 5.2 & 0.9 \\
\hline$\Sigma$ of the metabolites of DEHP & $\mathbf{3 2 . 1 6}(28.22 ; 36.64)$ & $\mathbf{6 1 . 8 8}(54.39 ; 70.41)$ & $36.72(32.26 ; 41.79)$ & $82.75(72.83 ; 94.02)$ & $32.40(27.56 ; 38.08)$ & $\mathbf{5 6 . 7 0}(48.80 ; 65.89)$ \\
\hline$\%<L O Q$ & 0 & 0 & 0 & 0 & 0 & 0 \\
\hline \multicolumn{7}{|l|}{ MCHP } \\
\hline$\%<L O Q$ & 98.3 & 89.2 & 98.4 & 98.4 & 98.3 & 99.2 \\
\hline \multicolumn{7}{|l|}{ MMP } \\
\hline$\%<L O Q$ & 80.3 & 58.3 & 90.4 & 70.1 & 67.8 & 53.0 \\
\hline
\end{tabular}

Note: CZ-Czech Republic, SK-Slovakia, HU-Hungary; N-number of subjects; \% < LOQ-the percentage of values below the quantification limit of the method.

${ }^{\text {a }} \Sigma$ of the metabolites of $\mathrm{DEHP}=5 \mathrm{OXO}-\mathrm{MEHP}+5 \mathrm{OH}-\mathrm{MEHP}$. 
Table 5

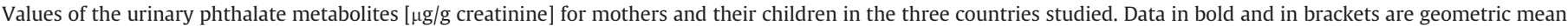
and $95 \%$ confidence interval.

\begin{tabular}{|c|c|c|c|c|c|c|}
\hline & \multicolumn{2}{|l|}{$\mathbf{C Z}$} & \multicolumn{2}{|l|}{ SK } & \multicolumn{2}{|l|}{ HU } \\
\hline & Mothers $(N=117)$ & Children $(N=120)$ & Mothers $(N=125)$ & Children $(N=127)$ & Mothers $(N=115)$ & Children $(N=117)$ \\
\hline MEHP & $3.13(2.70 ; 3.65)$ & $\mathbf{3 . 1 4}(2.71 ; 3.64)$ & $3.22(2.80 ; 3.69)$ & $\mathbf{3 . 2 6}(2.28 ; 3.77)$ & $3.70(2.60 ; 3.62)$ & $3.23(2.78 ; 3.75)$ \\
\hline$\%<L O Q$ & 23.9 & 27.5 & 20.0 & 22.1 & 25.2 & 24.8 \\
\hline 5ОН-МЕНР & $18.45(16.40 ; 20.75)$ & $37.69(33.97 ; 41.48)$ & $18.20(16.45 ; 20.14)$ & $40.69(36.55 ; 54.31)$ & $15.54(13.67 ; 17.67)$ & $29.77(26.29 ; 33.70)$ \\
\hline$\%<L O Q$ & 0 & 0 & 0 & 0 & 0 & 0 \\
\hline 5ОХО-МЕНР & $11.68(10.41 ; 13.10)$ & $25.25(22.71 ; 28.70)$ & $11.54(10.45 ; 12.75)$ & $27.46(24.57 ; 30.69)$ & $10.37(9.15 ; 11.74)$ & $20.27(17.86 ; 22.99)$ \\
\hline$\%<L O Q$ & 0 & 0 & 0 & 0 & 0 & 0 \\
\hline MEP & $53.28(42.03 ; 67.55)$ & $\mathbf{3 2 . 2 0}(27.28 ; 38.02)$ & $44.53(36.41 ; 54.46)$ & $32.72(28.40 ; 38.18)$ & $44.15(35.97 ; 54.19)$ & $41.56(34.15 ; 50.58)$ \\
\hline$\%<L O Q$ & 0 & 0 & 0 & 0 & 0 & 0 \\
\hline MBzP & $4.35(3,58 ; 5.29)$ & $8.48(7.18 ; 10.10)$ & $3.81(3.32 ; 4.39)$ & $6.89(5.96 ; 7.97)$ & $3.82(3.31 ; 4.40)$ & $\mathbf{6 . 7 0}(5.54 ; 8.90)$ \\
\hline$\%<L O Q$ & 9.4 & 0 & 4.8 & 0.8 & 5.2 & 0.9 \\
\hline$\sum$ of the metabolites of DEHP ${ }^{a}$ & $\mathbf{3 0 . 2 4}(26.95 ; 33.94)$ & $\mathbf{6 3 . 0 7}(56.85 ; 69.98)$ & 29.83 (26.99; 32.97) & $\mathbf{6 8 . 3 1}(61.30 ; 76.13)$ & $25.99(22.91 ; 29.48)$ & $\mathbf{5 0 . 1 6}(44.29 ; 56.82)$ \\
\hline$\%<L O Q$ & 0 & 0 & 0 & 0 & 0 & 0 \\
\hline \multicolumn{7}{|l|}{ MCHP } \\
\hline$\%<L O Q$ & 98.3 & 89.2 & 98.4 & 98.4 & 98.3 & 99.2 \\
\hline \multicolumn{7}{|l|}{ MMP } \\
\hline$\%<L O Q$ & 80.3 & 58.3 & 90.4 & 70.1 & 67.8 & 53.0 \\
\hline
\end{tabular}

Note: CZ-Czech Republic, SK-Slovakia, HU-Hungary; $N$-number of subjects; \% < LOQ-the percentage of values below the quantification limit of the method.

a $\Sigma$ of the metabolites of DEHP $=50 X 0-\mathrm{MEHP}+5 \mathrm{OH}-\mathrm{MEHP}$.

\subsection{Distribution of phthalate metabolites and differences among countries}

The concentrations of urinary phthalate metabolites are expressed in $\mu \mathrm{g} / \mathrm{L}$ urine (Table 4) and as the creatinine-corrected concentrations ( $\mu \mathrm{g} / \mathrm{g}$ creatinine) (Table 5 ).

Statistical significant differences in the volumetric concentrations $(\mu \mathrm{g} / \mathrm{L})$ of the metabolites 5-OH MEHP $(P<0.001)$, 50XOMEHP $(P<0.001)$, and sum of both $(P<0.001)$ were found only among children from the three countries, with a downward sequence of $\mathrm{SK}>\mathrm{CZ}>\mathrm{HU}$. Further statistical significant differences among children from the three countries were found for MEP with the highest concentration in HU $(P=0.015)$. (Fig. 1).

Weaker but still significant differences for the same metabolites (5-OH MEHP, $P=0.034$, 5OXO-MEHP, $P=0.051$ ), sum of both $(P=0.039)$ and MEP $(P=0.032)$ were found when creatinine was used as one of the covariates together with others (gender, vinyl flooring, industry with possible contamination of phthalates in neighbourhood of residence, milk consumption, main sources of drinking water, and use of personal care products). No differences
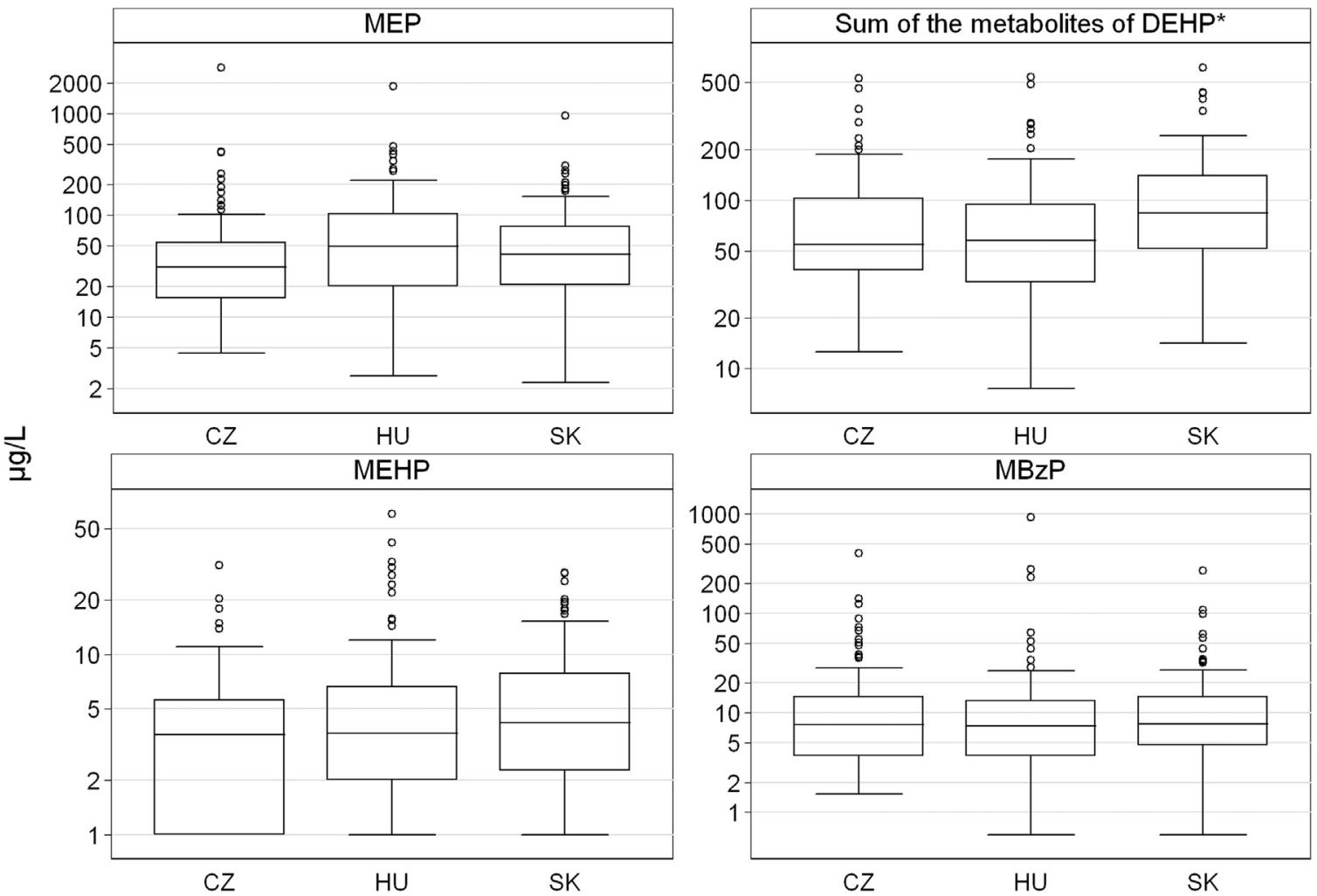

Fig. 1. Box and Whisker plots expressing phthalate metabolite concentrations $(\mu \mathrm{g} / \mathrm{L})$ in children from countries under investigation (logarithmic scale). 
were observed among the groups of mothers from the three countries either in unadjusted or in creatinine adjusted analyses.

However, the levels of creatinine in children and mothers differ among the countries with a sequence $\mathrm{CZ}<\mathrm{HU} \approx \mathrm{SK}(P=0.005)$.

\subsection{Gender-related differences in children}

Gender-related differences in the concentrations of phthalate metabolites were analysed separately for each country. In CZ boys had significantly higher concentrations of MEP $(P=0.002)$ and MBzP $(P=0.025)$ than girls. In HU boys had significantly higher concentrations of MEHP $(P=0.009)$. No significant gender-related differences were observed in children from SK.

\subsection{Lifestyle}

No differences among the three countries were observed in the consumption of hazelnut spread, convenience food, cereals, chocolate, local food, or other food items supposed to influence phthalate exposure (Heinemeyer et al., 2013). Other potential confounding factors such as smoking rate, alcohol consumption, and dietary habits could not explain any observed effects.

In this study, significant differences among mothers from the three countries were observed in the frequency of using make-up $(P<0.001)$, shampoo $(P<0.001)$, hair styling products $(P<0.001)$, body lotions and creams $(P<0.001)$. On the other hand, no differences were found in using eye make-up, fragrances, deodorants, massage oils, or nail polish. In children, significant differences were observed in the frequency of using shampoo $(P<0.001)$, which was lowest in HU. Slovak children used more frequently body lotions and creams $(P=0.012)$ than their peers in $\mathrm{CZ}$ or $\mathrm{HU}$. The parent compound DEP is commonly used in personal care products (Koniecki et al., 2011). Indeed, in each country, the frequency of using personal care products was significantly associated with the concentrations of MEP but more strongly in mothers $(P<0.001)$ than in children $(P=0.023)$. However, significant differences among countries in the MEP concentrations are only observed for children. Therefore the questions whether this single factor might explain the significantly higher levels of urinary metabolites in Slovak children compared to the CZ and HU needs further exploration.

\subsection{Behavioural factors}

Use of plastic products in households is considered an important exposure source to phthalates and in EU countries it is prohibited to market toys containing phthalates for children below 3 years of age. As all children in the DEMOCOPHES pilot study were older, they might have been in contact with toys containing phthalates. Nevertheless, playing with plastic toys was often reported less significantly for Slovak children than for children from Hungary $(P<0.001)$, which is in contradiction with the higher concentrations of phthalate metabolites found in Slovak children.

\subsection{Living area}

It is known that phthalates are ubiquitous components of the indoor environment (Wechsler and Nazaroff, 2008). PVC flooring was reported significantly more in $\mathrm{CZ}(P<0.001)$ than in SK and $\mathrm{HU}$ and urinary MBzP concentrations in both mothers and children were significantly related to the use of PVC flooring (Den Hond et al., unpublished data) but again this finding does not explain the higher concentrations of phthalate metabolites in SK.

Time spent daily in cars, use of bottled water or public sources and potentially contributing local industrial pollution cannot explain the observed differences for phthalate concentrations in children from SK that had (at least according to BQ) significant lower exposures to these potential sources than the other two countries $(P<0.05)$. Residence in urban or rural area did not show up as a significant exposure determinant $(P<0.05)$.

\subsection{Education}

The education of the study subjects was skewed towards a higher educational level expressed according to the International Standard Classification of Education (ISCED) categories. Whereas mothers with a tertiary education prevail in CZ and SK, slightly more mothers have secondary education in $\mathrm{HU}(P=0.051)$ not explaining the results observed for SK.

\subsection{Correlation of urinary metabolite concentrations between mo- thers and children}

In all three countries, moderate correlations between mother's and children's metabolite concentrations were observed while interestingly the correlations between mother and child appeared weaker in SK (Spearman correlation coefficients for different metabolites $0.13-0.34)$ than in $\mathrm{CZ}(0.21-0.56)$ and especially in $\mathrm{HU}$ (0.35-0.57) indicating that maybe there is a specific though yet unknown source of exposure for children in SK.

\subsection{Health-related limit values}

To put the results for the three countries in a more general health risk context, the proportion of individuals with biomarker levels above the existing health-based guidance values (Schulz et al., 2012) was calculated. The only existing health-based guidance values have been established by the German Human Biomonitoring Commission for the sum of two DEHP metabolites (5OH-MEHP $+50 X O-M E H P): 300 \mu \mathrm{g} / \mathrm{L}$ of urine for women of reproductive age and $500 \mu \mathrm{g} / \mathrm{L}$ of urine for children (Kasper-Sonnenberg et al., 2012; Schulz et al., 2007, 2011). The concentrations below these values are supposed not to be damaging to human health. In our study, the value of $300 \mu \mathrm{g} / \mathrm{L}$ was exceeded in only one $(0.9 \%)$ of 115 evaluated Hungarian mothers out of 357 total mothers included in all three countries. In children, the value of $500 \mu \mathrm{g} / \mathrm{L}$ was slightly exceeded only in one boy in each of the three countries.

\section{Conclusion}

The major objective of this paper was to explore whether significant differences in the urinary concentrations of phthalate metabolites among the populations of the Czech Republic, Hungary, and Slovakia exist.

To the best of our knowledge, the data on urinary phthalate metabolites obtained in DEMOCOPHES study are the first available for the three countries under study.

- Concentrations of some phthalate metabolites (5OH-MEHP, 5OXO-MEHP and sum of both metabolites) are significantly higher in Slovak children compared with the two other countries.

- The only factor that shows significant differences and therefore may explain the observations is the use of personal care products.

The results do indicate the importance of further human biomonitoring studies of phthalate exposure concentrations to be conducted in a sufficient number of children with different 
lifestyle characteristics and dietary habits in the three countries and possibly beyond.

\section{Acknowledgment}

The authors wish to thank the European Commission Directorate-General for Research and Innovation (RTD), that funded the COPHES project in the 7th Framework Program (No. 244237). The DEMOCOPHES project (LIFE09 ENV/BE/000410) received funding through the LIFE + financial instrument of the European Commission (DG ENV) as well as from different national funding agencies of the DEMOCOPHES countries. Thanks are also due to the Ministry of Education, Youth, and Sports of the Czech Republic for the support of Project no. 7EX11063. We also thank Vanessa. Peardon, Centre de Recherche Public-Gabriel Lippmann for editing the language of the manuscript.

\section{References}

Angerer, J., Ewers, U., Wilhelm, M., 2007. Human biomonitoring: state of the art. Int J. Hyg. Environ. Health 210, 201-228.

Au, W.W., 2002. Susceptibility of children to environmental toxic substances. Int. J. Environ. Health 205, 501-503.

ATSDR, 2002. Toxicological Profile for Di(2-ethylhexyl) Phthalate. Agency for Toxic Substances and Disease, Atlanta, GA.

Barr, D.B., Silva, M.J., Kato, K., Reidy, J.A., Malek, N.A., Hurtz, D., Sadowski, M., Needham, L.L., Calafat, A.M., 2003. Assessing human exposure to phthalates using monoesters and their oxidized metabolites as biomarkers. Environ. Health Perspect. 111, 1148-1151.

Becker, K., Schulz, C., Kaus, S., Seiwert, M., Seifert, B., 2002. Germen Environmental Survey 1998 (GerES III): environmental pollutants in blood of the German population. Int. J. Hyg. Environ. Health 205, 297-308.

Becker, K., Schulz, C., Kaus, S., Seiwert, M., Seifert, B., 2003. Germen Environmenta Survey 1998 (GerES III): environmental pollutants in urine of the German population. Int. J. Hyg. Environ. Health 206, 15-24.

Becker, K., Seiwert, M., Casteleyn, L., Joas, R., Joas, A., Biot, P., Aerts, D., Castaño, A Esteban, M., Angerer, J., Koch, H.M., Schoeters, G., Den Hond, E., Sepai, O., Exley, K., Knudsen, L.E., Horvat, M., Bloemen, L., Kolossa-Gehring, M., 2014. A systematic approach for designing a HBM Pilot Study for Europe. Int. J. Hyg. Environ. Health 217, 312-322. http://dx.doi.org/10.1016/j.ijheh.2013.07.004.

Blount, B.C., Milgram, K.E., Silva, M.J., Malek, N.A., Reidy, J.A., Needham, L.L.J.W., 2000. Quantitative Detection of Eight Phthalate Metabolites in Human Urine Using HPLC - APCI-MS/MS. Anal. Chem. 72, 4127-4134.

Cañas, A.I., Cervantes-Amat, M., Esteban, M., Ruiz-Moraga, M., Pérez-Gómez, B. Mayor, J., Castaño, A., 2014. Blood lead levels in a representative sample of the Spanish adult population: the BIOAMBIENT.ES project. Int. J. Hyg. Environ. Health 217, 452-459.

Centers for Disease Control and Prevention (CDC), 2013. Fourth National Report on Human Exposure to Environmental Chemicals. Updated Tables, September 2013. 〈http://www.cdc.gov/exposurereport/pdf/Fourth Report_UpdatedTables_Sep2013.pdf $\rangle$.

Černá, M., Spěváčková, V., Batáriová, A., Šmíd, J., Čejchanová, M., Očadlíková, D., Bavorová, H., Beneš, B., Kubínová, R., 2007. Human biomonitoring system in the Czech Republic. Int. J. Hyg. Environ. Health 210, 495-499.

EHAP, 2004. The European Environment \& Health Action Plan 2004-2010. COM 416. Available from: 〈http://ec.europa.eu/governance/impact/ia_carried_out/ docs/ia_2004/com_2004_0416_1_en.pdf .

Fiddicke, U., et al., Lessons learnt on recruitment and fieldwork from a pilot European biomonitoring survey. Environ. Res. http://dx.doi.org/10.1016/j.envres. 2014.08.039, this issue.

Fréry, N., Vandentorren, S., Etchevers, A., Fillol, C., 2012. Highlights of recent studies and future plans for the French human biomonitoring (HBM) programme. Int. J. Hyg. Environ. Health 215, 127-132.

Hauser, R., Calafat, A.M., 2005. Phthalates and human health. Occup. Environ. Med. 62, 806-818.
Heinemeyer, G., Sommerfeld, C., Springer, A., Heiland, A., Lindtner, O., Greiner, M., Heuer, T., Krems, C., Conrad, A., 2013. Estimation of dietary intake of bis(2ethylhexyl)phthalate (DEHP) by consumption of food in the German population. Int. J. Hyg. Environ. Health 216, 472-480.

Heudorf, U., Mersch-Sundermann, V., Angerer, J., 2007. Phthalates: toxicology and exposure. Int. J. Hyg. Environ. Health 210, 623-634.

Joas, R., Casteleyn, L., Biot, P., Kolossa-Gehring, M., Castano, A., Angerer, J., Schoeters, G., Sepai, O., Knudsen, L.E., Joas, A., Horvat, M., Bloemen, L., 2012. Harmonised human biomonitoring in Europe: activities towards an EU HBM framework. Int. J. Hyg. Environ. Health 215, 172-175.

Kasper - Sonnenberg, M., Koch, H.M., Wittsiepe, J., Wilhelm, M., 2012. Levels of phthalate metabolites in urine among mother-child-pairs-result from the Duisburg birth cohort study, Germany. Int. J. Hyg. Environ. Health 215, 373-382.

Koch, H.M., Drexler, H., Angerer, J., 2003a. An estimation of the daily intake of di(2ethylhexyl)phthalate (DEHP) and other phthalates in the general population. Int. J. Hyg. Environ. Health 206, 77-83.

Koch, H.M., Gonzalez-Reche, L.M., Angerer, J., 2003b. On-line cleanup by multidimensional LC-ESI-MS/MS for high throughput quantification of primary and secondary phthalate metabolites in human urine. J. Chromatogr. B 784 169-182.

Koch, H.M., Preuss, R., Angerer, J., 2006. Di(2-ethylhexyl)phthalate (DEHP): Human metabolism and internal exposure-an update and latest results. Int. J. Androl. 29, 155-165.

Koniecki, D., Wang, R., Moody, R.P., Zhu, J., 2011. Phthalates in cosmetic and personal care products: Concentrations and possible dermal exposure. Environ. Res. 111, 329-336.

Lyche, J.L., Gutleb, A.C., Bergman, Å, Eriksen, G.S., Murk, A.J., Ropstad, E., Saunders, M., Skaare, J.U., 2009. Reproductive and developmental toxicity of phthalates-a review. J. Toxicol. Environ. Health B Crit. Rev. 12, 225-249.

Needham, L., Calafat, A.M., Barr, D.B., 2007. Uses and issues of biomonitoring. Int. J. Environ. Health 210, 229-238.

Schindler, B.K., Esteban, M., Koch, M.H., Castano, A., Koslitz, S., Cañas, A., Casteleyn, L., Kolossa-Gehring, M., Schwedler, G., Schoeters, G., Den Hond, E., Sepai, O., Exley, K., Bloemen, L., Horvat, M., Knudsen, L.E., Joas, A., Joas, R., Biot, P., Aerts, D., Lopez, A., Huetos, O., Katsonouri, A., Maurer-Chronakis, K., Kasparova, L., Vrbik, K., Rudnai, P., Naray, M., Guignard, C., Fischer, M.E., Ligocka, D., Janasik, B., Reis, M.F., Namorado, S., Pop, C., Dumitrascu, I., Halzlova, K., Fabianova, E., Mazej, D., Tratnik, J.S., Berglund, M., Jönsson, B., Lehmann, A., Crettaz, P., Frederiksen, H., Nielsen, F., McGrath, H., Nesbitt, I., De Cremer, K., Vanermen, G., Koppen, G., Wilhelm, M., Becker, K., Angerer, J., 2014. The European COPHES/ DEMOCOPHES project: towards transnational comparability and reliability of human biomonitoring results. Int. J. Hyg. Environ. Health 217, 653-661. http: //dx.doi.org/10.1016/j.ijheh.2013.12.002.

Schneiderka, P., Pacáková, V., Stulík, K., Kloudová, M., Jelínková, K., 1993. Highperformance liquid chromatographic determination of creatinine in serum, and a correlation of the results with those of the Jaffé and enzymic methods. J. Chromatogr. 614, 221-226.

Schulz, C., Angerer, J., Ewers, U., Kolossa-Gehring, M., 2007. The German human biomonitoring commission. Int. J. Hyg. Environ. Health 210, 373-382.

Schulz, C., Wilhelm, M., Heudorf, U., Kolossa-Gehring, M., 2011. Update of the reference and HBM values derived by the German Human Biomonitoring Commission. Int. J. Eviron. Health 215, 26-35.

Schulz, C., Wilhelm, M., Heudorf, U., Kolossa-Gehring, M., 2012. Reprint of "Update of the reference and HBM values derived by the German Human Biomonitoring Commission". Int. J. Eviron. Health 215, 150-158.

Swan, S.H., Main, K.M., Liu, F., Steward, S.L., Kruse, S.L., Calafat, A.M., Mao, C.S. Redmon, J.B., Ternand, C.L., Sullivan, S., Teague, J.L., 2005. Decrease in anogenital distance among male infants with prenatal phthalate exposure. Environ. Health Perspect. 113 (8), 1056-1061.

Wechsler, C.J., Nazaroff, W., 2008. Semivolatile organic compounds in indoor environments. Atmos. Environ. 42, 9018-9040.

WHO, 1996. Biological Monitoring of Chemical Exposure in the Workplace. vol. 1. World Health Organization, Geneva.

Wittassek, M., Koch, H.M., Angerer, J., Brüning, T., 2011. Assessing exposure to phthalates-the human biomonitoring approach. Molecular Nutrition 55, 7-31. http://dx.doi.org/10.1002/mnfr.201000121.

Zimmer, K.E., Gutleb, A.C., Ravnum, S., Kreyer von Krauss, M., Murk, A.J., Ropstad, E., Skaare, J.U., Eriksen, G.S., Koppe, J.G., Magnanti, B.L., Yang, A., Bartonova, A., Keune, H., 2012. Policy relevant results from an expert elicitation on the health risks of phthalates. Environ. Health 11 (Suppl. 1), S6. 